\title{
Oral 5-ASA versus prednisone in short term treatment of Crohn's \\ disease: A multicentre controlled trial
}

\author{
F MARTIN, MD, L SUTHERLAND, MD, IT BECK, MD, AH ANDERSON, MD,
}

CN WILLIAMS, MD, F SAIBIL, MD, J BARROWMAN, MD, S LEMIRE, MD

\begin{abstract}
A multicentre randomized controlled trial was designed to compare the efficacy and safety of Eudragit-L coated oral 5 -aminosalicylic acid (5-ASA) (Salofalk; Interfalk) $3 \mathrm{~g}$ per day to a 'standard' oral prednisone therapeutic regimen in a 12 week treatment period of uncomplicated attacks of Crohn's ileitis and ileocolitis. Fifty patients with active Crohn's disease (Crohn's disease activity index [CDAI] 200 to 450) were randomized to receive either four $250 \mathrm{mg}$ Eudragit-L-100 coated 5-ASA tablets three times a day for 12 weeks or oral prednisone ( $4 \mathrm{mg}$ tablets) at a sustained $40 \mathrm{mg}$ per day for two weeks followed by a $4 \mathrm{mg} /$ day weekly dose reduction for the 10 subsequent weeks. Efficacy was determined by changes in the calculated CDAI and, as a novel assessment, the McMaster University quality of life index at two, four, six, eight, 10 and 12 weeks. Standard blood and urine values were obtained and physician's assessment completed at each two week visit. Clinical remission was obtained in 12 of 26 patients $(46 \%)$ in the prednisone group and in nine of $19(47 \%)$ in the 5-ASA group. Treatment failure was observed in three patients in each group. All other patients improved during the treatment period. Patients on prednisone reduced their CDAI scores significantly more rapidly during the first four weeks, but the reduction and maintenance of CDAI scores were similar in both groups for the remainder of the study period. In patients with ileocolitis, prednisone was significantly better than 5-ASA. Quality of life assessment parallelled the changes in CDAI, and appear a valid index. The two therapeutic regimens appear safe and did not disclose any unexpected adverse events or side effects. No significant biological abnormalities were detected in either treatment group. In conclusion, in this small trial, it was found that Salofalk at a dose of $3 \mathrm{~g}$ per day appears effective treatment for active Crohn's disease, and it is proposed that higher doses may be beneficial in more extensive disease (ileocolitis) and during the first four weeks of treatment. Can J Gastroenterol 1990;4(7):452-457 (pour résumé, voir page 453)
\end{abstract}

Key Words: Mesalamine, Oral corticosteroids, Prednisone

Division of Gastroenterology, Hôpital St-Luc, Université de Montréal, Montréal, Québec; Faculty of Medicine, University of Calgary, Calgary, Alberta; Division of Gastroenterology, Queen's University, Kingston, Ontario; Division of Gastroenterology, Dalhousie University, Halifax, Nova Scotia; Division of Gastroenterology, Sunnybrook Hospital, Toronto, Ontario; Faculty of Medicine, Memorial University of Newfoundland, St John's, Newfoundland; and Hôpital l'Enfant-Jésus, Université Laval, Québec City, Québec

Correspondence and reprints: Dr F Martin, Faculty of Medicine, University of Montréal, Chief of GI Services, Hôpital Saint-Luc, 1058 St-Denis St, Montréal, Québec H2X $3 J 4$.

Telephone (514) $281-3564$
HE TREATMENT OF UNCOMPLI.
cated attacks of Crohn's disease in an outpatient setting is mostly pharmacological, and includes both oral and parenteral corticosteroids and sulphasalazine. Two recent multicentre cooperative studies compared pred. nisone, sulphasalazine and placebo $(1,2)$. In these studies, oral prednisone or 6-methylprednisolone given for 17 weeks was most effective in treating active Crohn's ileitis and ileocolitis.

Sulphasalazine has been shown to have some clinical benefit in patients with small bowel disease, but due to the colonic bacterial reduction needed for the release of the active moiety, 5 . aminosalicylic acid (5-ASA) (3), sulphasalazine is more useful in patients with Crohn's disease of the colon. Moreover sulphasalazine efficacy is dose-dependent and patients often cannot tolerate sufficient doses for an optimal therapeutic response due to the sulfapyridine moiety's relative toxicity.

Although effective in reducing symptoms and creating a somewhat artificial sense of general well-being in patients with active disease, oral corticosteroids are not devoid of several potentially dangerous side effects which are dependent on dose and duration of therapy (4).

Recent enthusiasm has emerged for the use of several new oral 5.ASA agents in the treatment of inflammatory bowel disease (5). Salofalk ( $\mathrm{In}$ terfalk) is one oral 5-ASA preparation 


\section{Efficacité et sécurité comparées de l'acide 5-aminosalicylique oral et de la prednisone dans le traitement à court terme de la maladie de Crohn. Essai contrôlé multicentrique}

RESUME: On a procédé à un essai contrôlé randomisé multicentrique afin de comparer l'efficacité et la sécurité d'emploi de l'acide 5-aminosalicylique administré sous forme de comprimés d'Eudragit-L (Salofalk; Interfalk) enrobés à la dose de $3 \mathrm{~g}$ par jour d'une part; et une cure «standard" de prednisone orale d'autre part, dans le traitement des poussées non compliquées d'iléite et d'iléocolite de Crohn, poursuivi sur une période de 12 semaines. Cinquante patients porteurs de maladie de Crohn active (indice d'activité de la maladie de Crohn [CDAI] 200 à 450) et randomisés ont reçu soit quatre comprimés de $250 \mathrm{mg}$ de 5-ASA (Eudragit-L-100) enrobés trois fois par jour pendant 12 semaines, soit des comprimés de prednisone de $4 \mathrm{mg}$ à la dose de $40 \mathrm{mg}$ par jour pendant deux semaines, réduite à $4 \mathrm{mg}$ par jour pendant les dix semaines suivantes. L'efficacité a été déterminée en fonction des changements relevés au CDAI et par une nouvelle mesure, le McMaster University Quality of Life Index à deux, quatre, six, huit, 10 et 12 semaines. Les analyses usuelles de sang et d'urine, et l'évaluation du médecin ont été effectuées toutes les deux semaines. Une rémission clinique a été atteinte chez 12 des 26 patients (46\%) sous prednisone et chez neuf des 19 patients $(47 \%)$ sous 5-ASA. L'échec du traitement a été constatée chez trois patients de chaque groupe. Tous les autres malades se sont améliorés en cours de traitement. Les patients traités sous prednisone ont obtenu une réduction significativement plus rapide de leurs résultats $\mathrm{CDAI}$ durant les quatre premières semaines, mais la réduction et le maintien des scores CDAI étaient similaires dans les deux groupes pour le reste de l'étude. Chez les patients porteurs d'iléocolite, la prednisone s'est avérée significativement supérieure au 5-ASA. L'évaluation de la qualité de vie était parallèle aux changements du CDAI et semble donc constituer une mesure valide. Les deux schémas posologiques semblent sûrs et n'ont donné lieu à aucun événement inattendu ni effets secondaires indésirables. Aucune anomalie biologique significative n'a été relevée dans l'un ou l'autre groupe. En conclusion, ce petit essai démontre que le Salofalk administré à la dose de $3 \mathrm{~g}$ par jour semble efficace dans le traitement de la malade de Crohn évolutive; il suggère qu'une posologie plus élevée serait peut-être bénéfique dans le traitement d'une affection plus étendue (iléo-colite) et au cours des quatre premières semaines du traitement.

in which a slow release system is obtained by compressing finely dispersed 5-ASA with sodium carbonate and glycerine and protecting this core with an enteric coating (Eudragit-L). The breakdown point for release of 5-ASA in this preparation is at a $\mathrm{pH}$ greater than 5.6. Thus 5-ASA is allegedly delivered progressively in the jejunum and distal small bowel.

The first report suggesting potential therapeutic efficacy for Salofalk in the short term treatment of active Crohn's disease came from Maïer and colleagues (6). In this randomized trial, they compared Salofalk $1.5 \mathrm{~g}$ per day to sulphasalazine $3 \mathrm{~g}$ per day in 30 patients during an eight week treatment period. They observed that $87 \%$ of the Salofalk patients and $80 \%$ of the sulphasalazine patients 'improved' as determined by a mean reduction of the clinical activity scores of $61 \%$ for Salofalk and $47 \%$ for sulphasalazine.

The same group then performed another controlled trial comparing $3 \mathrm{~g}$ Salofalk daily to a combination therapy of methylprednisolone $40 \mathrm{~g}$ per day for one week followed by a $4 \mathrm{mg}$ weekly reduction plus a constant dose of 3 g per day of sulphasalazine for 12 weeks (7). In this clinical trial, the reported therapeutic success was remarkably high; $83 \%$ of the patients taking Salofalk and $88 \%$ taking combination therapy were said to have achieved remission at the end of the 12 week period.

The present authors designed a multicentre clinical trial to compare the relative efficacy and safety of $3.0 \mathrm{~g}$ Salofalk daily to a 'standard' oral prednisone 12 week treatment period in patients with active ileitis and ileocolitis.

\section{PATIENTS AND METHODS}

Fifty patients from eight centres entered the study. Men and nonpregnant, nonlactating women over 18 years of age participated. Patients with active, uncomplicated Crohn's ileitis or ileocolitis were eligible if, at screening visit, the Crohn's disease activity index (CDAI) (8) score was between 200 and 450 points. Diagnostic confirmation of Crohn's disease with ileal involvement was obtained at entry or within the previous 12 months by small bowel follow-through barium meal and barium enema and/or by colonoscopy and biopsy.

Patients with confirmed infectious enterocolitis, internal or external fistulas, esophageal, gastric or jejunal disease, Crohn's colitis alone, prior bowel resection or clinically significant hepatic, renal, cardiovascular or respiratory disease were excluded from the study. Patients were also excluded if they had received active Crohn's disease treatment within the previous month; however, patients who were already taking oral prednisone at a maximum of $10 \mathrm{mg}$ per day for at least one month were allowed in the trial providing that the dose was kept unchanged during the trial period.

This was a 12 week, randomized, double-blind, parallel group, multicentre study. Candidate patients were first seen for a screening visit. Physician's evaluation included medical history and physical examination; blood and urine samples were collected for standard analysis and stools for cul. ture. Selection criteria were revised for eligibility and informed consent signed. Screened patients were then released and asked to record daily for one week the number of liquid stools, a numerical rating of abdominal pains and of their general well-being for the calculation of the baseline CDAI score. If the criteria were met for the trial after this screening week, each patient was randomly assigned to receive either four 250 mg Eudragit-L-100 coated 5-ASA tablets (Salofalk) three times a day for 12 weeks or oral prednisone in $4 \mathrm{mg}$ 
TABLE 1 Study population of a multicentre controlled trial of 5-ASA versus prednisone
in active Crohn's disease

\begin{tabular}{lcc}
\hline & Prednisone $(\mathbf{n = 2 8})$ & 5-ASA (n=22) \\
\hline Mean age in years (range) & $30.6(19-62)$ & $29.2(19-60)$ \\
Sex (male/female) & $10 / 18$ & $9 / 13$ \\
Disease characteristics & $18 / 10$ & $12 / 10$ \\
Ileitis/ileocolitis & 2.4 & 5.3 \\
Mean disease duration (years) & 8 & 1 \\
First episode & 3.4 & 4.1 \\
Number of previous episodes & 6.1 & 6.5 \\
Duration of current episode (months) & & $295 \pm 81$ \\
Pretrial disease activity & $291 \pm 71$ & $134 \pm 35$ \\
CDAl (mean \pm SD) & $129 \pm 25$ & 7 \\
QOLI (mean \pm SD) & 6 & \\
Concomitant low dosage prednisone & & \\
(10 mg or less) & & \\
\hline n Number of patients; CDAl Crohn's disease activity index; QOL Quality of life index
\end{tabular}

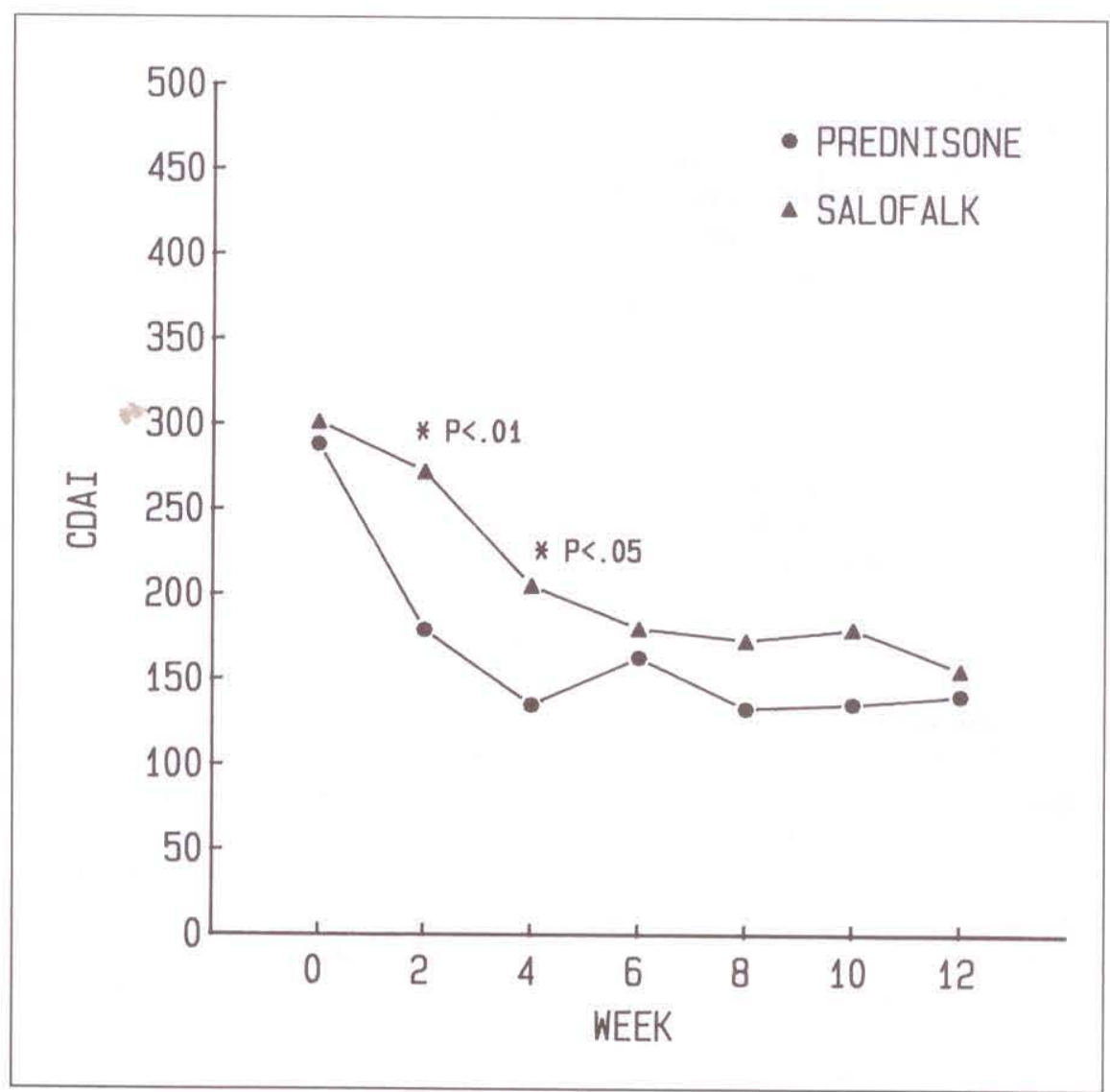

Figure 1) Mean Crohn's disease activity index (CDAI) score changes obtained at each two week visit in all studied patients in a multicentre controlled trial of 5-aminosalicylic acid versus prednisone

tablets at a sustained $40 \mathrm{mg}$ per day for two weeks followed by a $4 \mathrm{mg}$ per day weekly dose reduction for the 10 subsequent weeks.

Each patient returned every two weeks for 12 weeks. At each visit, physician's global assessment and physical examination were completed, and CDAI score calculated. In addition, as a novel assessment, each patient had to answer a set of 32 questions relating to the quality of life experienced during the past two treatment weeks (McMaster University quality of life index) (9).

Efficacy assessment was determined
TABLE 2

Comparative therapeutic efficacy of prednisone and 5-ASA in Crohn's disease

\begin{tabular}{lll}
\hline & $\begin{array}{c}\text { Prednisone } \\
(\mathbf{n}=26)\end{array}$ & $\begin{array}{l}\text { 5-ASA } \\
(\mathrm{n}=19)\end{array}$ \\
\hline Remission & $12(46 \%)$ & $9(47 \%)$ \\
Improved* & 11 & 7 \\
Failure & 3 & 3 \\
\hline
\end{tabular}

"Reduction in Crohn's disease activity index.n Number of patients

by the major variable changes in the calculated CDAI from baseline to final visit. Remission was considered achieved if the final CDAI score was less than 150 points. Clinical deterioration, confirmed by an increase or ab. sence of reduction of the CDAI score, or any serious side effect occurring during the trial period which prompted the patient and the treating physician to terminate the study, were considered treatment failures.

\section{RESULTS}

Patient's disposition: A total of 50 patients entered the study. Treatment groups were comparable with respect to age, sex, disease characteristics and severity (Table 1). Six patients in the prednisone group and seven in the Salofalk group continued to take a constant dose of $10 \mathrm{mg}$ prednisone during. the trial.

Three Salofalk patients were not in. cluded by protocol stipulations, and two prednisone patients were lost to follow-up during the first week of the study; these five patients are excluded from efficacy and safety analysis.

Therapeutic efficacy: The major variable changes in the calculated CDAI from baseline to final visit for the two treatment groups are shown in Figure 1 . A statistically significant greater reduction in the CDAI scores was achieved by the higher doses of prednisone during the first four weeks, but thereafter and until the 12th week, the two treatment modalities achieved and maintained an equivalent mean reduction of CDAI values close to the remission score of 150. Comparative treatment outcome is summarized in Table 2. Clinical remission, strictly determined by a CDAI score of 150 or 


\section{ILEITIS}

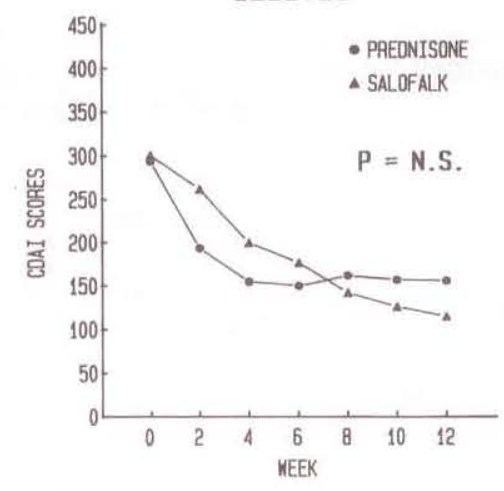

ILEOCOLITIS

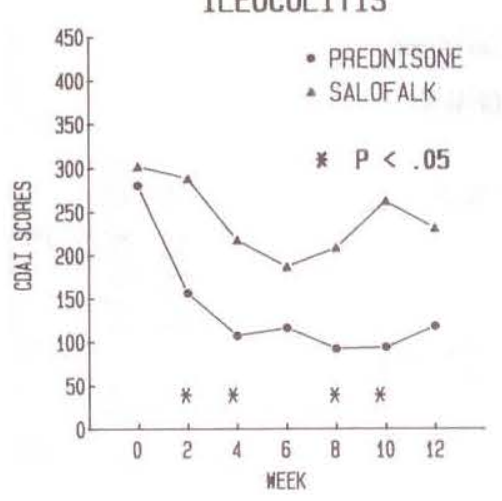

Figure 2) Mean Crohn's disease activity index (CDAI) score changes obtained at each two week visit in patients with ileitis and ileocolitis in a multicentre controlled trial of 5 -aminosalicylic acid versus prednisone

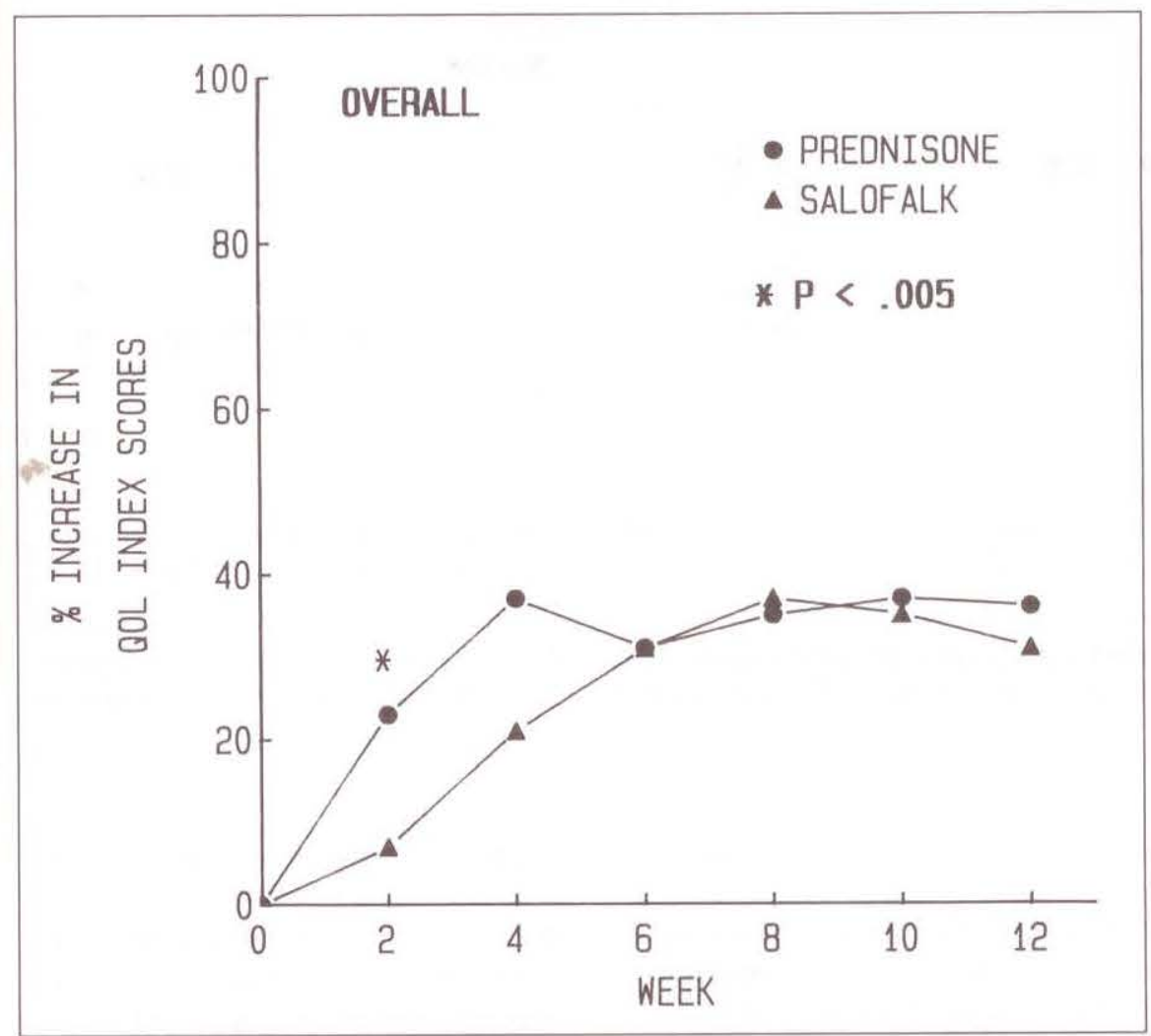

Figure 3) Mean percentage increase from baseline values of the quality of life (QOL) index scores obtained at each two week visit in all patients in a multicentre controlled trial of 5-aminosalicylic acid versus prednisone

below at the end of the 12 week study, was achieved in nine of the 19 Salofalk patients $(47 \%)$ and in 12 of the 26 prednisone patients $(46 \%)$. Treatment failure due to therapeutic insufficiency before or after completion of treatment was observed in three patients in each treatment group, determined either by increased or unchanged CDAI values

from baseline or by the physician's clinical decision. All other patients were clinically improved, confirmed by a reduction in their CDAI scores compared to pretrial values.

The therapeutic response with respect to site of disease has been analyzed separately and the changes in CDAI values are shown in Figure 2. In patients with ileitis alone, the two therapeutic regimens were not different in reducing CDAI scores over the 12 weeks. In the ileocolitis group, however, prednisone was significantly better than Salofalk in reducing CDAI at almost every follow-up visit $(\mathrm{P}<0.05)$. Quality of life assessment: Patients' quality of life, determined by the McMaster quality of life index (19), improved concomitantly with clinical improvement as expected. However, when the percentage increases in the overall scores both treatment groups were compared, prednisone patients achieved 20 and $40 \%$ increases in the quality of life index at weeks 2 and 4 , respectively, and seemed to maintain this level of improvement for the remaining weeks of the study, while Salofalk patients had a significantly more modest increase of 6 and $24 \%$ at weeks 2 and 4, respectively (Figure 3 ). At six weeks and thereafter until study termination, the percentage increases were not different in either treatment group ( $35 \%$ and $40 \%$ ). When the subscores of the quality of life index (relating to bowel symptoms, systemic symptoms, social functions and emotional function) were compared, only the systemic symptoms were significantly less influential on the quality of life in the second week in the prednisone patients compared to the Salofalk patients (Figure 4). The somewhat artificial sense of well-being of patients on high dose prednisone during the first four weeks of the study might explain this apparent advantage of prednisone over Salofalk.

Adverse events: Serious adverse events which led to early termination were observed in three prednisone and two Salofalk patients. One prednisone patient had severe headaches after two weeks, another developed severe intercostal herpes zoster in week 4 , and the last had severe Cushingoid symptoms after eight weeks. One Salofalk patient terminated participation early when she presented with a concomitant viral hepatitis after four weeks. The other Salofalk patient terminated participation after two weeks because of headaches, continuous vomiting and a CDAI score of 497. Table 3 lists the 


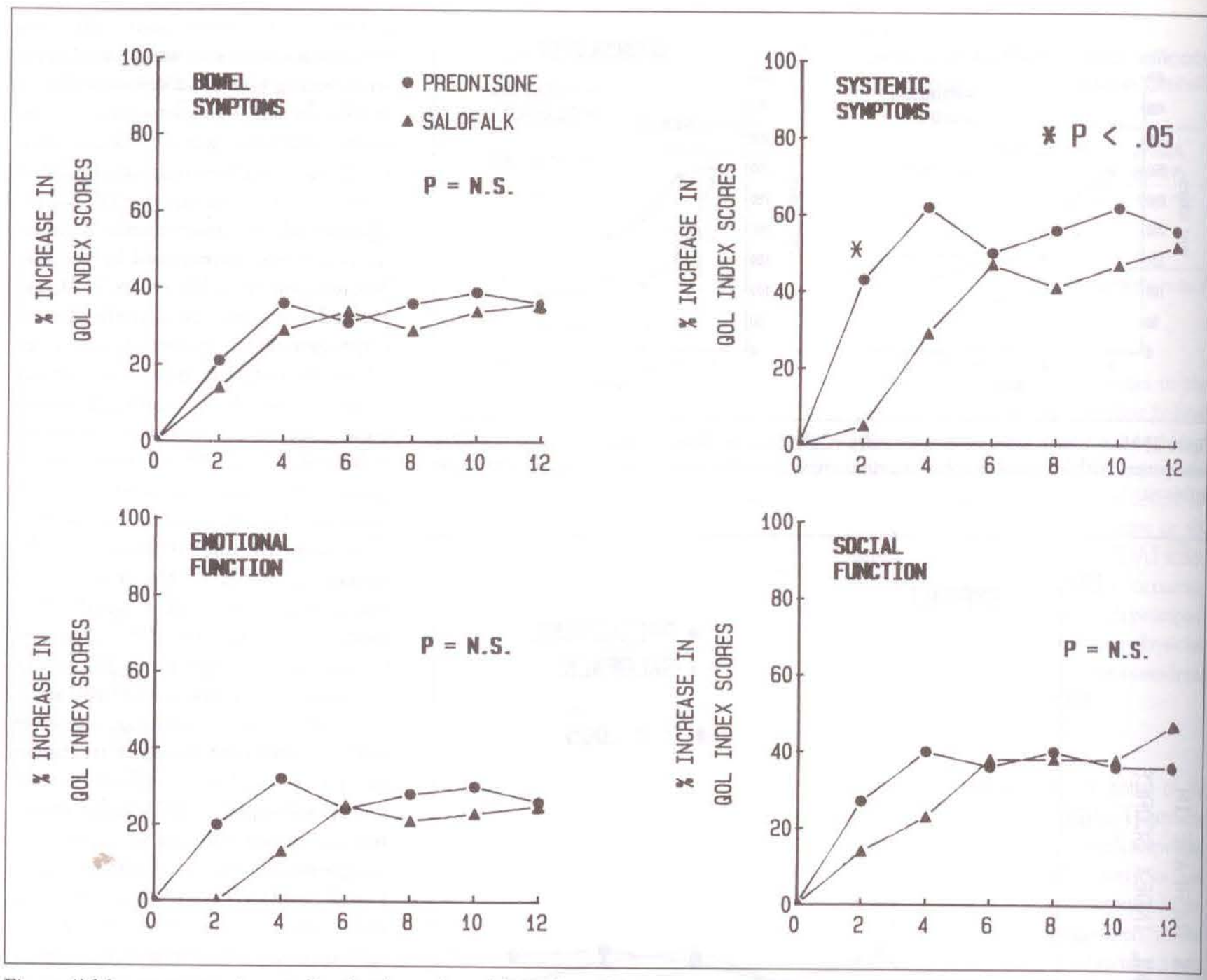

Figure 4) Mean percentage increase from baseline values of the quality of life (QOL) index subscores relating to bowel symptoms, systemic symptoms, emotional function and social function obtained in all patients at each two week visit in a controlled multicentre trial of 5-aminosalicylic acid versus prednisone

minor side effects that were reported in both groups; none was clinically significant.

\section{DISCUSSION}

Admittedly this controlled trial tested too few patients to contribute any firm conclusions on the comparative therapeutic efficacy of Salofalk $3 \mathrm{~g}$ per day versus 'standard' therapy with prednisone in the short term treatment of active uncomplicated Crohn's ileitis and ileocolitis. Despite this apparent short coming, the study can nonetheless provide useful information about the therapeutic potential of oral 5 . ASA preparations and provide several lessons for the design and conduct of future studies in a field of investigation where standard trial practice is far from universally established.

The major therapeutic goal of treating acute attacks of uncomplicated Crohn's disease is to achieve clinical remission and to improve the patient's quality of life. For almost 30 years, oral corticosteroids have been widely used clinically to achieve remission, and two recent multicentre studies confirm their efficacy $(1,2)$. However, in order to demonstrate the superiority or at least equivalence of an alternate drug modality to oral corticosteroids, a minimum of 350 patients should be admitted to a comparative trial. The present small trial is helpful as it provides useful information on the potential optimal dose of 5-ASA with respect to initial activity and to anatomical extension of the disease. Indeed, at the end of the 12 week treatment period, Salofalk given at a fixed dose of $3 \mathrm{mg}$ per day appeared almost equivalent to standard oral prednisone therapy when the overall treatment groups were compared (Table 2, Figure 1); however, further analysis suggests that a higher dose of 5-ASA during the first four weeks of therapy might be necessary, as it is for oral prednisone.

In addition, as the oral 5-ASA preparations are dependent for efficacy on the quantity of drug delivered at the site of inflammation, it is not unexpected that patients with more extensive disease as in ileocolitis (Figure 2) will respond less favorably when taking 
TABLE 3

\begin{tabular}{|c|c|c|c|}
\hline & $P$ & $5-A S A+P$ & 5-ASA \\
\hline Hyperactivity & 2 & 0 & 0 \\
\hline Insomnia & 3 & 1 & 1 \\
\hline Headache & 3 & 1 & 0 \\
\hline Tiredness & 2 & 0 & 0 \\
\hline Edema & 3 & 1 & 0 \\
\hline Acne & 2 & 0 & 0 \\
\hline Candidiasis & 1 & 0 & 0 \\
\hline Nausea & 0 & 1 & 1 \\
\hline Total & 16 & 4 & 1 \\
\hline
\end{tabular}

PPrednisone: 5-ASA+P 5-ASA plus $10 \mathrm{mg}$ or less prednisone

a fixed dose of $3 \mathrm{~g}$ per day of Salofalk. A higher dose of 5-ASA is perhaps necessary for patients with more extensive ileocolic disease.

The apparent low remission rate obtained by both treatment modalities in the present study compared to the classic report of the National Cooperative Crohn' s Disease study (NCCDS) (1) deserves some consideration. The remission rates achieved by prednisone and sulphasalazine in the NCCDS report were 60 and $45 \%$, respectively, and are considered by many as the 'gold standard' of efficacy for these agents in active Crohn's disease. First, in the

\section{REFERENCES}

1. Summers RW, Switz DM, Sessions JT Jr, et al. National Cooperative Crohn's disease study: Results of drug treatment. Gastroenterology 1979;77:847-69.

2. Malchow HK, Ewe K, Brandes JW, et al. European Cooperative Crohn's disease study (ECCDS): Result of drug treatment. Gastroenterology 1984;86:249-66.

3. Khan AKA, Piris J, Truelove SC. An experiment to determine the active therapeutic moïety of sulphasalazine. Lancet 1977;ii:892-5.
NCCDS, the treatment period for active disease (phase I) was 17 weeks. On inspection of the results curve for remission rate at 12 weeks, the remission rate for the prednisone group was $48 \%$ compared to $28 \%$ for sulphasalazine. Second, in the NCCDS the mean pretrial CDAI scores are $17 \%$ lower than in the present treatment groups, which could obviously influence treatment outcome at 12 weeks. Third, the initial dose of prednisone was modulated according to pretrial severity of the attack as determined by the pretrial CDAI score and the patient's weight. Initial maximum doses, as high as $60 \mathrm{mg}$ prednisone and $5 \mathrm{~g}$ sulphasalazine have been administered. In the present study, the pre-established doses of prednisone and Salofalk were applied to all patients regardless of clinical activity or weight. Therefore, the authors are convinced that their results are not out of range, and for the purpose of comparison between trials, they suggest that a new study design include the preceding considerations.

A therapeutic efficacy assessment of any modality should evaluate concomitantly its effect on the quality of life of the treated patients. In the present study, a recently proposed 'quality of life index' was tested and its apparent validity confirmed inasmuch

4. Meyers S. Oral and parenteral steroids. In : Peppercorn MA, ed. Therapy of Inflammatory Bowel Disease. New York: Marcel Dekker Inc, 1990:3-34.

5. Martin F. Oral 5-ASA preparations. In: Bayless TM, ed. Current Management of Inflammatory Bowel Disease.Toronto: BC Decker Inc, 1989:72-7.

6. Maïer K, Fruehmorgen P, Bode CJ, et al. Successful management of chronic inflammatory gut disease with oral 5-aminosalicylic acid. Dtsch Med Wochenschr 1985;110:363-8. as it parallelled the clinical activity scores, and in that the comparative analysis of the subscores relating to groups of symptoms or functions were in agreement with overall evaluation. More specifically the better efficacy of higher dose prednisone during the first four weeks was reflected significantly by the quality of life index.

Too few serious adverse events were observed during the study to justify conclusions or fair comparison of the two treatment modalities. Fewer minor side effects were reported in the Salofalk group compared to the prednisone group and the prednisone/ Salofalk group (Table 3), but none was of serious significance.

In conclusion, this study strongly suggests that oral 5-ASA, more specifically Salofalk at a minimum dose of $3 \mathrm{~g}$ per day, is efficacious in treating acute attacks of Crohn's ileitis and ileocolitis. Perhaps higher doses of the drug should be given during the first four weeks of therapy in all patients, and higher dose regimens should also be considered in patients with more extensive bowel involvement, namely ileocolitis. If these dose modulations are proved effective in future clinical trials, it is foreseeable that oral 5-ASA therapy could become an effective, less toxic therapeutic approach for active Crohn's disease than standard prednisone treatment.

7. Maïer K, Frick HJ, Von Gaisberg U, Teufel T, Klotz U. Clinical efficacy of oral mesalazine in Crohn's disease. Can J Gastroenterol 1990;4:13-8.

8. Best WR, Becktel JM, Singleton JW, Kern F. Development of a Crohn's disease activity index. National Cooperative Crohn's Disease Study. Gastroenterology 1976;70:439-44.

9. Guyatt G, Mitchell A, Irvine JE, et al. A new measure of health status for clinical trials in inflammatory bowel disease. Gastroenterology 1989;96:804. 10. 


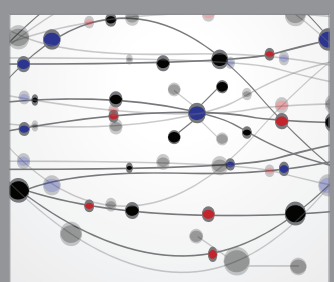

The Scientific World Journal
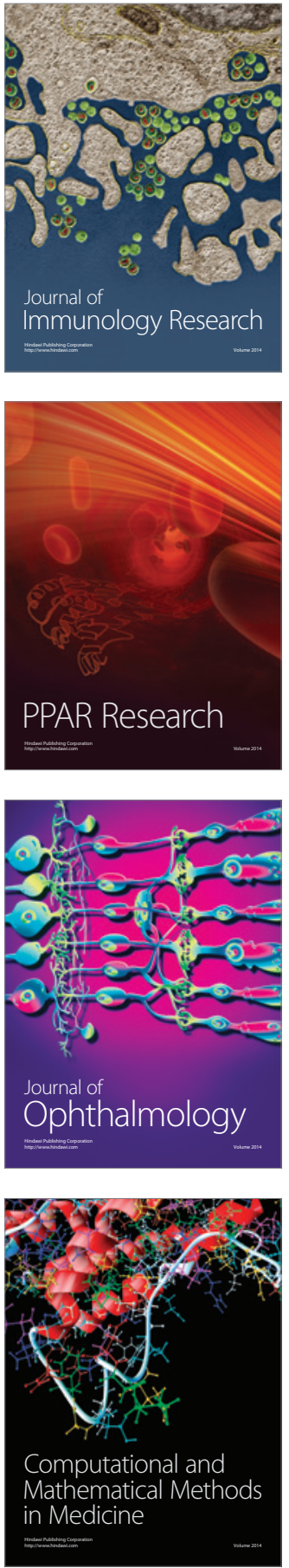

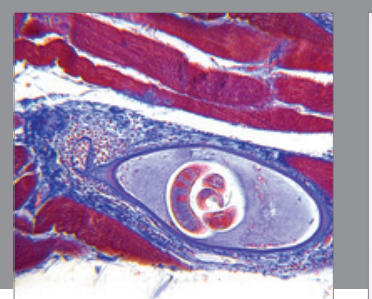

Gastroenterology Research and Practice

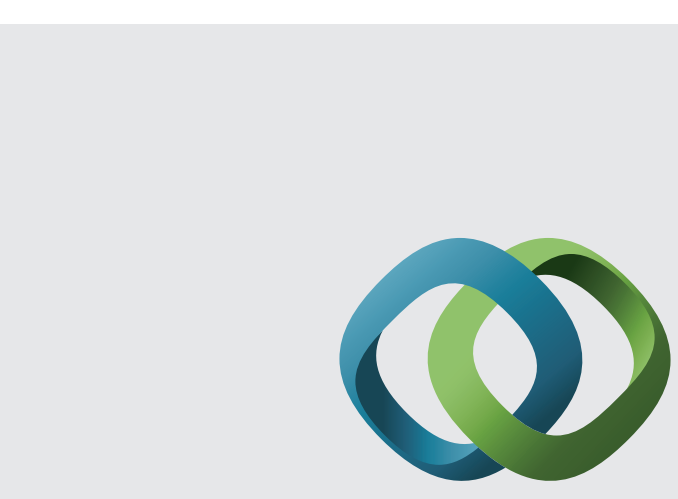

\section{Hindawi}

Submit your manuscripts at

http://www.hindawi.com
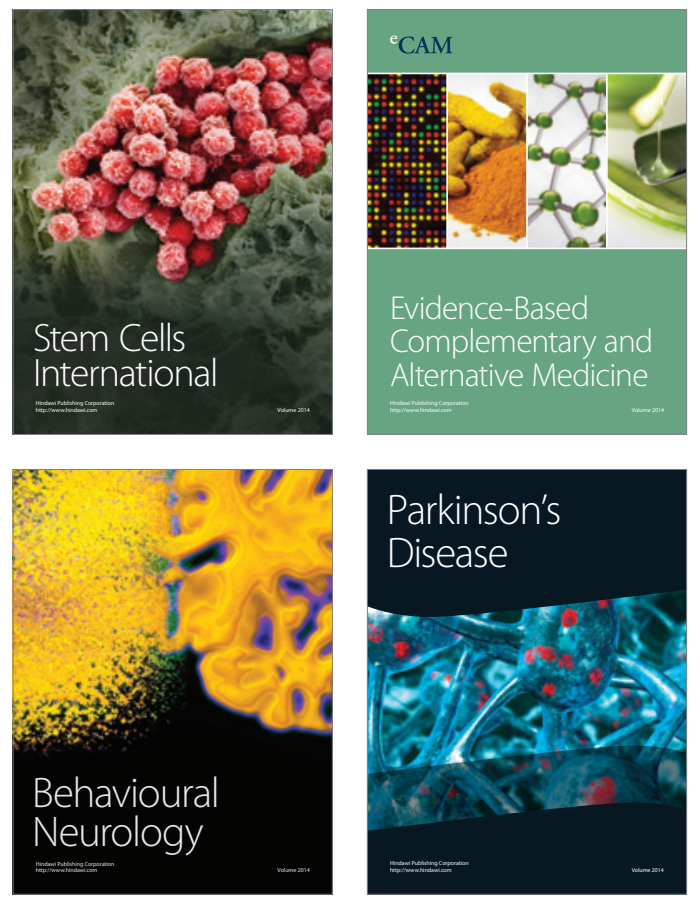
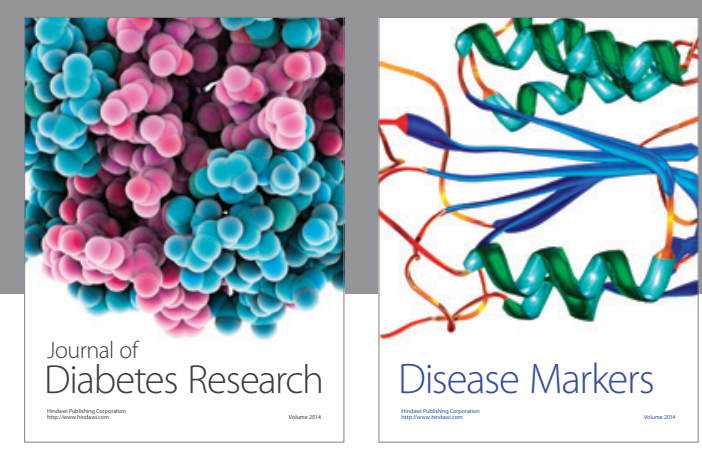

Disease Markers
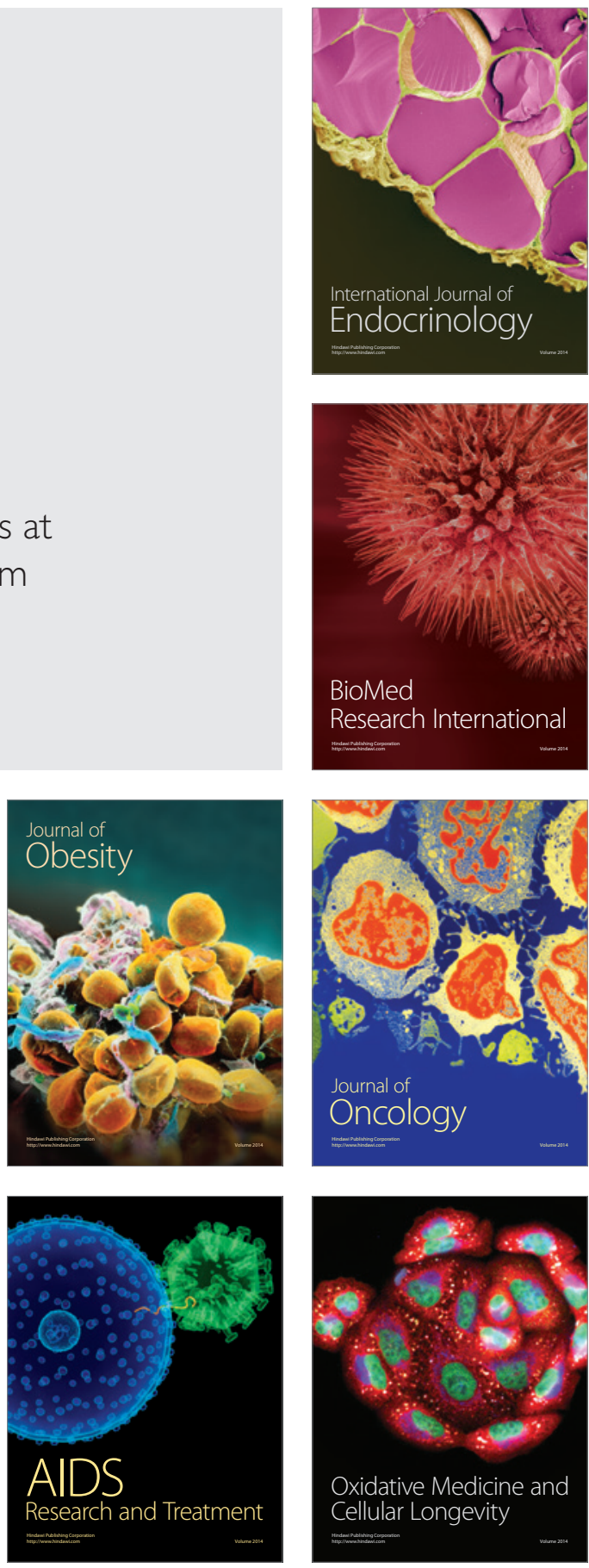